\title{
PLANEJAMENTO E PROGRAMAÇÃO LOCAL EM SAÚDE COMO METODOLOGIA DE ENSINO-APRENDIZAGEM NO CURSO DE MEDICINA
}

\section{EXPERIENCE REPORT ON LOCAL PLANNING AND PLANNING IN HEALTH (PPLS) AS TEACHING-LEARNING IN THE MEDICINE COURSE.}

\section{Lorena Vieira Fernandez de Araújo, Rosangela Souza Lessa, Rafaela Fontes Costa}

Faculdade independente do Nordeste - FAINOR

\begin{abstract}
This study seeks to describe the teaching-learning experiences developed by students of the second period of medical course in the elaboration of a Local Health Planning and Programming (PPLS) aimed at the registered community of a Family Health Unit (USF). This is an experience report, carried out in a community registered at the Family Health Unit. The PPLS methodology was developed through a workshop with users present and identification of the problem pointed out by the community. As a result, it presented the construction of the PPLS spreadsheets, with the listing and prioritization of problems, development of objectives, analysis of their feasibility, and operative programming, aimed at guiding the adolescents and adults of the USF's registered community about the risks, consequences and measures protective measures of drug use and abuse. The abuse of alcohol and other drugs is a global problem, which causes losses in the biopsychosocial scope, requiring interventionist measures to minimize its problems. The elaboration of the PPLS allowed the student to get closer to the reality of the community, developing the planning of activities that will help the population in their confrontation and social transformation.
\end{abstract}

Keywords: Health Policy, Planning and Management; Primary Care, Drugs.

\section{Resumo}

Esse estudo busca descrever as experiências do ensinoaprendizagem desenvolvida por discentes do curso de medicina na elaboração de um Planejamento $e$ Programação Local em Saúde (PPLS). Trata-se de um relato de experiência, realizado em uma comunidade adscrita na Unidade de Saúde da Família. Desenvolveuse a metodologia do PPLS por meio de uma oficina com usuários presentes e identificação da problemática apontada pela comunidade. Apresentou como resultado a construção das planilhas, com a listagem $e$ priorização dos problemas, desenvolvimento dos objetivos, análise da sua viabilidade, e programação operativa, direcionadas para orientar os adolescentes e adultos da comunidade adscrita da USF acerca dos riscos, consequências e medidas protetivas do uso $e$ abuso de drogas. O abuso de álcool e outras drogas é um problema global, que causa prejuízos no âmbito biopsicossocial, necessitando de medidas intervencionistas para minimização dos seus agravos. A elaboração do PPLS permitiu uma maior aproximação do estudante com a realidade da comunidade, desenvolvendo o planejamento de atividades que ajudarão a população no seu enfrentamento e transformação social.

Palavras-chave: Politicas, Planejamento e Administração em Saúde; Atenção Básica, Drogas. 
Historicamente, 0 processo saúde/doença advêm de um conceito curativista associado a um modelo biomédico. Nessa perspectiva, buscava-se apenas a cura sem uma visão holística do indivíduo, negligenciando os determinantes do processo de adoecimento da população que influenciam nas condições de saúde e de seus fatores de risco. Contudo, a prática da saúde alcançou mudanças significativas, especialmente, após a Constituição de 1988 e a criação do Sistema Único de Saúde (SUS), com a implementação da Atenção Básica $(A B)$ no atendimento aos usuários. $A \quad A B$ constitui-se em um conjunto de ações que dão consistência prática ao conceito de Vigilância em Saúde, que articula conhecimentos e técnicas provindos da epidemiologia, do planejamento e das ciências sociais em saúde, redefinindo as práticas em saúde, articulando as bases de promoção, proteção e assistência, a fim de garantir a integralidade do cuidado ${ }^{1,2}$.

Em concordância com a ideia do cuidado implementado com a Atenção Básica, as graduações dos cursos de Medicina têm modificado suas metodologias de ensinoaprendizagem no intuito de permitir uma formação humanizada, com aproximação precoce do aluno à realidade da comunidade, e, além disso, fornecer ao discente um conhecimento do funcionamento da rede do SUS, para que, dentro de seu âmbito profissional, esteja apto a desenvolver ações de prevenção, promoção, proteção e reabilitação da saúde, em nível individual e coletivo ${ }^{3}$.

A adoção do Planejamento e a Programação Local em Saúde (PPLS), então, é uma estratégia de aproximar discentes e profissionais da realidade vivenciada pelo usuário. O PPLS é um método de planejamento estratégico situacional para Vigilância em Saúde, que tornam os usuários ativos das modificações sociais na qual estão inseridos. Este método se baseia na definição de objetivos a partir de problemas identificados, análise da viabilidade e da estratégia de sua solução, com o objetivo de desenvolver processos, técnicas ou atitudes administrativas que permitam as modificações de situações futuras por meio de ações presentes ${ }^{4}$. Portanto, para a elaboração do PPLS é necessário realizar um diagnóstico situacional para identificar problemas atuais e futuros; identificar e definir prioridades de intervenção para implementar soluções; descrever e explicar os problemas; definir estratégias para solucionar os problemas e elencar os responsáveis pelo desenvolvimento destas ações; e avaliar e monitorar a implementação da ação, bem como os resultados 5

Ademais, compreendendo o usuário do serviço de saúde como sujeito ativo dentro do processo saúde/doença, bem como o gestor e os gerentes do sistema de saúde6, percebe-se a capacidade do PPLS de tornar este usuário protagonista dessa construção social e, portanto, o planejamento é a base para uma integração da atenção básica com a vigilância e para uma indissociabilidade dessa atenção com a gestão ${ }^{7}$.

Dessa forma, esse estudo visa descrever as experiências vivenciadas pelos discentes do curso de medicina na elaboração de um PPLS voltado para comunidade adscrita uma Unidade de Saúde da Família (USF), como técnica de aprendizagem, da disciplina Integração Ensino, Serviço e Comunidade (IESC).

\section{Metodologia}

Trata-se de um relato de experiência elaborado a partir da construção de um PPLS em uma USF. O trabalho teve o envolvimento de seis discentes de medicina, uma preceptora, a comunidade e os profissionais da unidade de Saúde. A USF selecionada, apresenta cerca de 4161 famílias, divididas em duas equipes de assistência. A equipe 1 com 1931 e a equipe 2 com 2230 famílias cadastradas. As equipes são constituídas de médicos, enfermeiros, técnicos de enfermagem, odontólogos, auxiliar de saúde bucal, técnica em farmácia e agentes comunitários de saúde (ACS). A comunidade apresenta renda média a baixa, com nível educacional variável (desde graduação a analfabetos). O fluxo diário de usuários é em média de 100 pessoas ao dia.

Após contato com a unidade, foram distribuídos convites a comunidade, pelos ACS, convidando-os para que pudessem participar da oficina a ser realizada, a fim de levantar e priorizar os principais problemas de saúde existentes. A oficina ocorreu na sala de espera da USF, contando com a participação de 12 usuários, dos quais aceitaram o convite para participar da oficina.

Os discentes explanaram, para os presentes, como se daria a oficina e, em seguida, a população elencou os problemas relacionados à saúde da comunidade, por meio da chuva de ideias. Cada problema listado pelos participantes foi anotado pela relatora. Tal metodologia permitiu a seleção de prioridades, pela visão do 
sujeito ativo, na identificação dos problemas que afligem a comunidade recorrentemente. Posterior a definição dos problemas, foi feita a triagem para identificar as problemáticas de maior relevância, a partir da contabilização do número de pessoas que classificavam cada situação de saúde como mais urgente e cabível de intervenção pelos discentes ${ }^{8}$.

Após esse momento, houve a escolha da transcendência, que remete à importância do problema e sua priorização como algo que necessita de intervenção imediata ou não, bem como permite a definição da magnitude, valorização, tecnologia disponível e custo, indicativos estes que auxiliam no processo de planejamento necessário para intervenção de problemas na comunidade. A votação foi desenvolvida a partir de plaquinhas, através da diferenciação de cores nas quais determinavam se o problema era considerado de alta (vermelho), média (amarelo) ou baixa (verde) frequência, determinando assim a magnitude e valorização em relação a cada problema determinado.
Em seguida, determinou-se, pelos discentes em reunião grupal, as tecnologias disponíveis e o custo, referente à quantidade de recursos disponíveis para a resolução do problema de acordo com o grau de vulnerabilidade do problema a ser solucionado. Essa etapa deveria ser realizada também por votação da comunidade, mas ficou evidente a dificuldade dos mesmos no entendimento e votação desse item (Quadro 1). Feita a tabulação e priorização dos problemas do estado de saúde da população, os três problemas indicados pela comunidade participante foram: Alta frequência de depressão entre adolescentes na comunidade (terceiro lugar); Alta frequência de problemas de saúde bucal na comunidade (segundo lugar) e Alta frequência no consumo de álcool e outras drogas entre adolescentes e adultos da comunidade (primeiro lugar).

Quadro 1: Priorização de problemas do estado de saúde da população adscrita a USF, Vitória da

Conquista - BA, 2019.

\begin{tabular}{|l|c|c|c|c|c|c|}
\hline Problema & M & V & TC & C & T & R \\
\hline $\begin{array}{l}\text { Alta frequência no consumo de álcool e } \\
\text { outras drogas entre adolescentes e } \\
\text { adultos da comunidade adscrita da } \\
\text { Unidade de Saúde da Família, em 2019.1 }\end{array}$ & 3 & 3 & 3 & 3 & 12 & $\mathbf{1 0}$ \\
\hline $\begin{array}{l}\text { Alta frequência de problemas de saúde } \\
\text { bucal na comunidade adscrita da Unidade } \\
\text { de Saúde da Família, em 2019.1 }\end{array}$ & 2 & 2 & 3 & 3 & 10 & $\mathbf{2 0}$ \\
\hline $\begin{array}{l}\text { Alta frequência de depressão entre } \\
\text { adolescentes na comunidade adscrita da } \\
\text { Unidade de Saúde da Família, em 2019.1 }\end{array}$ & 1 & 3 & 2 & 2 & 8 & 3o \\
\hline
\end{tabular}

Legenda: M: Magnitude; V: Valorização; TC: Tecnologia disponível; C: Custo; T: Total; R: Resultado obtido.

$\mathrm{Na}$ etapa seguinte, foi construída a árvore de problemas. O problema priorizado localizado no tronco da árvore, as causas na raiz e as consequências nos galhos e folhas (Figura 1). A partir daí, em um momento posterior, os acadêmicos traçaram os objetivos geral e específicos a partir das causas apontadas na árvore, elaborando assim a "árvore de objetivos", que visou propor ações de intervenção para o problema selecionado (Quadro 2). Assim, o objetivo geral proposto para construção das planilhas do PPLS foi orientar os adolescentes e adultos da comunidade adscrita da USF acerca 
dos riscos, consequências e medidas protetivas do uso e abuso de drogas.

Figura 1: Árvore de problemas

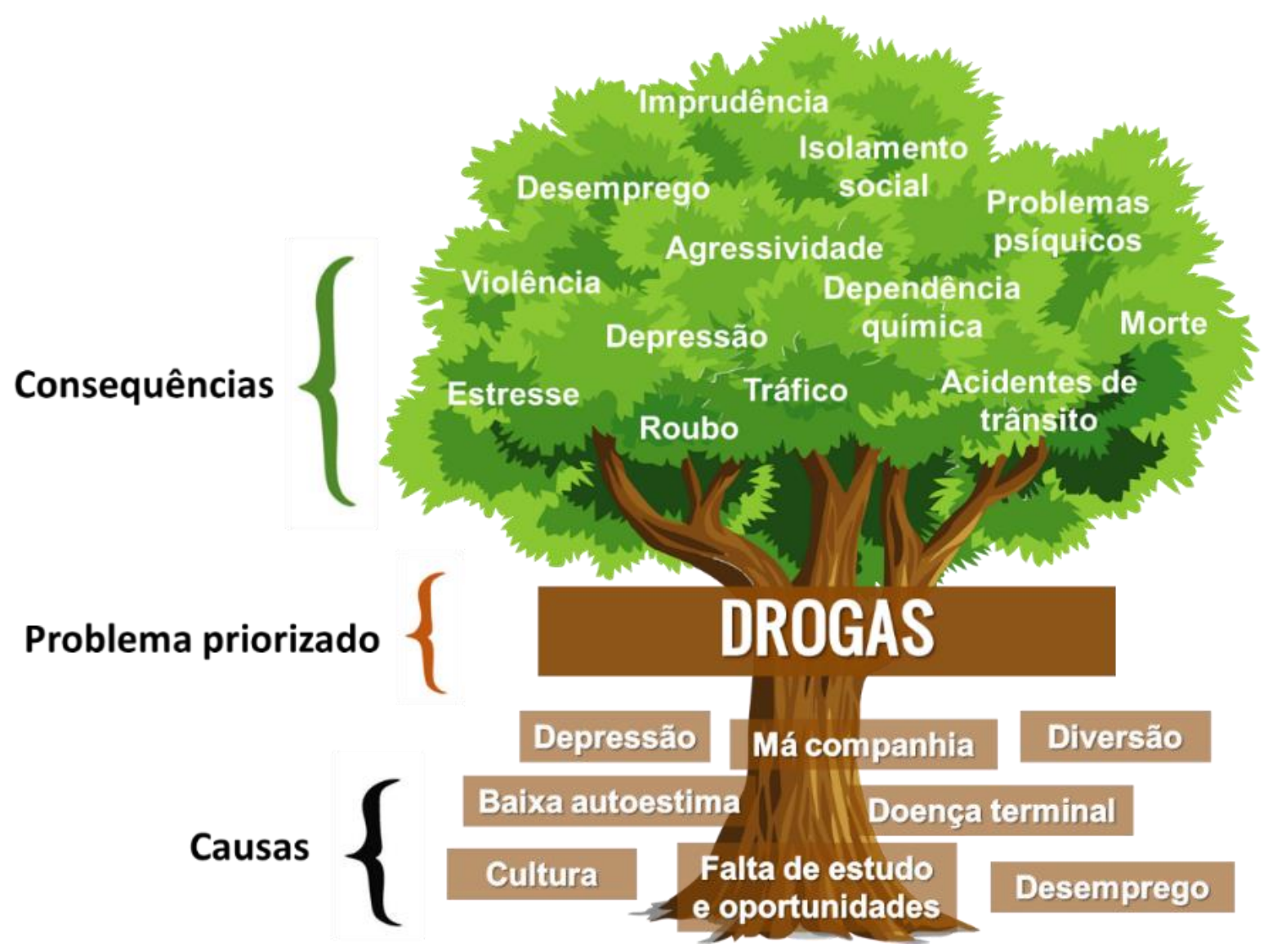


Quadro 2: Árvore de objetivos do estado de saúde da população adscrita a USF.

\begin{tabular}{|l|l|}
\hline \multicolumn{1}{|c|}{ Problema } & \multicolumn{1}{c|}{ Objetivos } \\
\hline $\begin{array}{l}\text { Alta frequência no } \\
\text { consumo de álcool e } \\
\text { outras drogas entre } \\
\text { adolescentes e adultos } \\
\text { da comunidade adscrita } \\
\text { da Unidade de Saúde da }\end{array}$ & $\begin{array}{l}\text { Objetivo geral: } \\
\text { Orientar os adolescentes e adultos da comunidade adscrita da USF acerca } \\
\text { em 2019.2. } \\
\text { Oamília, em 2019.1 }\end{array}$ \\
$\begin{array}{l}\text { Oo Inforivos específicos: } \\
\text { sobre o efeito, fatores de risco e as consequências da droga no organismo, } \\
\text { em 2019.2. } \\
\text { 20 Orientar a comunidade adscrita da USF a prática de exercício físico } \\
\text { como alternativa para prevenção do uso/abuso de drogas em 2019.2. } \\
\text { 30 Facilitar a discussão precoce dos adolescentes com a temática drogas } \\
\text { nas Escolas do território da USF, em 2019.2. } \\
\text { 40 Favorecer o diálogo e interação entre pais e filhos na comunidade } \\
\text { adscrita da USF, em 2019.2. } \\
\text { 50 Qualificar o corpo docente das escolas adscritas ao território da USF } \\
\text { acerca da percepção de baixa autoestima, bem como a abordagem ao } \\
\text { discente usuário, em 2019.2. }\end{array}$ \\
\hline
\end{tabular}

Dando continuidade a construção do PPLS, os discentes confeccionaram a "análise da viabilidade", descrevendo as ações, facilidades, dificuldades e as estratégias para superarem as dificuldades (Quadro 3). Além disso, a "programação operativa" e os "Indicadores de acompanhamento e avaliação da programação operativa" foram construídos (Quadro 4) ${ }^{3}$. Os indicadores foram explicitados por números ou proporções, por exemplo, quantidade de presentes na oficina e demonstrados pelas fontes de verificação como listas de frequência e relatórios, sendo posteriormente divulgados os resultados para a comunidade e equipe de saúde (mural da USF, reuniões da equipe e conselhos). Esses indicadores servem para verificar uma determinada situação ocorrida ${ }^{8}$.

Quadro 3: Análise de viabilidade, Programação operativa e Indicadores de Acompanhamento e Avaliação da Programação Operativa

\begin{tabular}{|c|c|c|c|c|c|}
\hline \multicolumn{6}{|c|}{ Análise de Viabilidade } \\
\hline Objetivo Específico & Ação & Facilidade & Dificuldade & Estratégia & \\
\hline \multirow[t]{2}{*}{ 1ㅇ objetivo } & $\begin{array}{lr}\text { 1a } & \text { Ação: } \\
\text { Roda } & \text { de } \\
\text { conversa } & \text { na } \\
\text { sala } & \text { de } \\
\text { espera } & \text { da } \\
\text { USF } & \end{array}$ & $\begin{array}{l}\text { Presença da } \\
\text { comunidade na } \\
\text { sala de espera }\end{array}$ & $\begin{array}{l}\text { Dispersão da } \\
\text { comunidade e } \\
\text { falta de } \\
\text { compreensão }\end{array}$ & $\begin{array}{l}\text { Dinâmicas } \\
\text { participativas } \\
\text { ilustrativas }\end{array}$ & $\mathrm{e}$ \\
\hline & $\begin{array}{l}2 \text { a Ação: } \\
\text { Teatro com } \\
\text { fantoches na } \\
\text { escola }\end{array}$ & $\begin{array}{l}\text { Presença do } \\
\text { aluno na escola }\end{array}$ & $\begin{array}{l}\text { Atenção dos } \\
\text { alunos }\end{array}$ & $\begin{array}{l}\text { Linguagem } \\
\text { adequada } \\
\text { roteiro }\end{array}$ & do \\
\hline
\end{tabular}


Continuação.

\begin{tabular}{|c|c|c|c|c|c|c|}
\hline 2ㅇ Objetivo & $\begin{array}{l}\text { 3a Ação: } \\
\text { Prática de } \\
\text { exercícios } \\
\text { físicos }\end{array}$ & $\begin{array}{l}\text { Existência da } \\
\text { academia da } \\
\text { saúde na USF }\end{array}$ & \multicolumn{2}{|c|}{$\begin{array}{l}\text { Profissional de } \\
\text { educação física }\end{array}$} & \multicolumn{2}{|c|}{$\begin{array}{l}\text { Agendar } \\
\text { previamente com } \\
\text { a profissional }\end{array}$} \\
\hline 3ㅇo Objetivo & $\begin{array}{l}\text { 4a Ação: } \\
\text { Intervalo } \\
\text { interativo }\end{array}$ & $\begin{array}{ll}\text { Local } & \text { de } \\
\text { realização } & \end{array}$ & $\begin{array}{l}\text { Conduçã } \\
\text { atividade } \\
\text { adesão } \\
\text { alunos }\end{array}$ & $\begin{array}{r}\text { da } \\
\text { e } \\
\text { dos }\end{array}$ & \multicolumn{2}{|c|}{$\begin{array}{lr}\text { Distribuir } & \text { as } \\
\text { tarefas entre } & \text { os } \\
\text { membros } & \text { do } \\
\text { grupo } & \text { e } \\
\text { elaboração } & \text { do } \\
\text { material } & \\
\text { adequando } & \\
\text { estratégias } & \text { para } \\
\text { adesão. } & \end{array}$} \\
\hline 4o Objetivo & $\begin{array}{l}\text { 5a Ação: } \\
\text { Gincana na } \\
\text { escola }\end{array}$ & $\begin{array}{ll}\text { Local } & \text { de } \\
\text { realização } & \end{array}$ & $\begin{array}{l}\text { Falta } \\
\text { adesão } \\
\text { pais }\end{array}$ & $\begin{array}{r}\text { de } \\
\text { dos }\end{array}$ & \multicolumn{2}{|c|}{$\begin{array}{l}\text { Realização da } \\
\text { ação no mesmc } \\
\text { dia da reunião de } \\
\text { pais }\end{array}$} \\
\hline 5o Objetivo & $\begin{array}{l}\text { 6a Ação: } \\
\text { Capacitação } \\
\text { dos } \\
\text { professores }\end{array}$ & $\begin{array}{l}\text { Local de } \\
\text { realização e a } \\
\text { existência dos } \\
\text { professores }\end{array}$ & $\begin{array}{l}\text { Compatit } \\
\text { e do hor } \\
\text { corpo do } \\
\text { Psicóloge } \\
\text { CAPS }\end{array}$ & $\begin{array}{l}\text { lidad } \\
\text { io do } \\
\text { ente } \\
\text { do }\end{array}$ & \multicolumn{2}{|c|}{$\begin{array}{l}\text { Articulação com a } \\
\text { direção da escola; } \\
\text { agendar com } \\
\text { antecedência }\end{array}$} \\
\hline \multicolumn{7}{|c|}{ Programação Operativa } \\
\hline Objetivo Específico & Ação & \multicolumn{2}{|c|}{ Atividade } & \multicolumn{2}{|c|}{ Responsável } & Prazo \\
\hline \multirow[b]{2}{*}{ 10 objetivo } & $\begin{array}{ll}\text { Roda } & \text { de } \\
\text { conversa } & \text { na } \\
\text { sala } & \text { de } \\
\text { espera } & \text { da } \\
\text { USF } & \end{array}$ & \multicolumn{2}{|c|}{$\begin{array}{l}\text { 1. Elaboração da dinâmica } \\
\text { 2. Fabricação de cartazes } \\
\text { 3. Elaborar e aplicar } \\
\text { questionário } \\
\text { 4. Aplicar pós teste } \\
\text { 5. Tirar fotos durante o } \\
\text { evento }\end{array}$} & \multicolumn{2}{|c|}{ Acadêmicos } & $\begin{array}{c}04 / 09 / \\
2019\end{array}$ \\
\hline & $\begin{array}{l}\text { Teatro com } \\
\text { fantoches na } \\
\text { escola }\end{array}$ & \multicolumn{2}{|c|}{$\begin{array}{l}\text { 1. Agendamento com a } \\
\text { escola } \\
\text { 2. Confecção dos } \\
\text { fantoches } \\
\text { 3. Elaboração do roteiro } \\
\text { 4. Preparação do lanche } \\
\text { 5. Tirar fotos durante o } \\
\text { evento }\end{array}$} & \multicolumn{2}{|c|}{ Acadêmicos } & $\begin{array}{c}11 / 09 / \\
2019\end{array}$ \\
\hline 2o Objetivo & $\begin{array}{l}\text { Prática de } \\
\text { exercícios } \\
\text { físicos }\end{array}$ & \multicolumn{2}{|c|}{$\begin{array}{l}\text { 1. Agendamento prévio } \\
\text { com o profissional } \\
\text { educador físico } \\
\text { 2.Confecção de convites } \\
\text { para a comunidade } \\
\text { 3. Preparação das } \\
\text { atividades } \\
\text { 4. Coletar depoimento dos } \\
\text { participantes } \\
\text { 5. Tirar fotos durante o } \\
\text { evento }\end{array}$} & \multicolumn{2}{|c|}{ Acadêmicos } & $\begin{array}{c}18 / 09 / \\
2019\end{array}$ \\
\hline
\end{tabular}




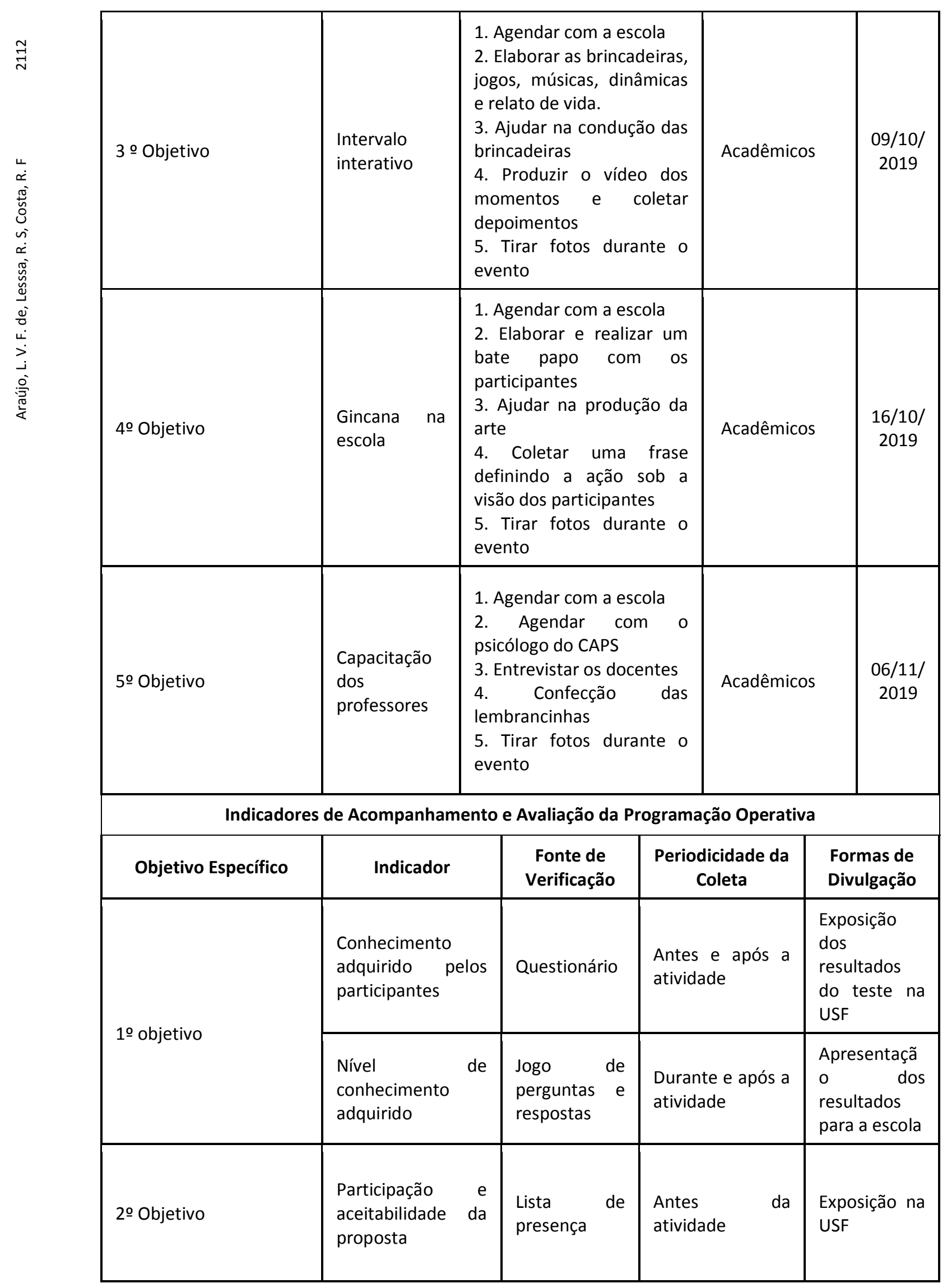


Continuação.

\begin{tabular}{|c|c|c|c|c|}
\hline $3 \cong$ Objetivo & $\begin{array}{l}\text { Envolvimento dos } \\
\text { presentes. }\end{array}$ & $\begin{array}{l}\text { Observação e } \\
\text { depoimento } \\
\text { de alunos. }\end{array}$ & $\begin{array}{l}\text { Durante e depois } \\
\text { da atividade }\end{array}$ & $\begin{array}{l}\text { Exposição na } \\
\text { escola }\end{array}$ \\
\hline 4으이etivo & $\begin{array}{l}\text { Participação dos } \\
\text { pais e filhos }\end{array}$ & $\begin{array}{l}\text { Relato dos } \\
\text { pais e filhos }\end{array}$ & $\begin{array}{l}\text { Durante e após } \\
\text { atividade }\end{array}$ & $\begin{array}{l}\text { Apresentaçã } \\
\text { o dos } \\
\text { resultados } \\
\text { para a escola }\end{array}$ \\
\hline 5ㅇ Objetivo & $\begin{array}{l}\text { Conhecimento } \\
\text { adquirido }\end{array}$ & Entrevistas & $\begin{array}{l}\text { Antes e após a } \\
\text { atividade }\end{array}$ & $\begin{array}{l}\text { Exposição de } \\
\text { um banner } \\
\text { na escola }\end{array}$ \\
\hline
\end{tabular}

\section{Discussão}

O Planejamento e a Programação Local em Saúde é uma potente ferramenta na construção do aprendizado e remete a importância da sua adequação frente a realidade do serviço de saúde de cada localidade. A atenção básica em seu caráter preventivo remete a minimização dos riscos e melhoria da qualidade de vida dos seus usuários, orientando para atividades de planejamento, antecipando problemas e evitando o caráter surpresa das intercorrências em saúde ${ }^{7}$.

O PPLS permite a identificação dos problemas elencados como prioritários na comunidade e que necessitam de intervenções ${ }^{6}$. Dessa forma, ações foram planejadas para um público-alvo, no intuito de sensibilizar a população acerca dos riscos oriundos do uso de consumo elevado de álcool e outras drogas na comunidade. A partir da árvore dos problemas, relatado pela comunidade, observa-se a preocupação com as consequências provocadas pelo problema priorizado: violência, desemprego, isolamento social, problemas psíquicos, mortalidade, acidentes de trânsito, marginalidade e estresse. A comunidade identificou as possíveis causas para os problemas, a exemplo, a depressão, baixa autoestima, má companhia, falta de oportunidade, como fuga para doença terminal, desemprego e para uso recreativo.

O álcool e outras drogas, eleito como prioridade, é uma adversidade que acomete uma grande parcela da população com consequências individuais e coletivas, físicas, psíquicas e social, com crescente aumento do seu consumo entre adolescentes ${ }^{9}$.

Nesse contexto, o consumo de substâncias psicoativas (SPAs) vem se expandindo mundialmente, o que interfere não só a nível biológico, mas em todo o contexto biopsicossocial do indivíduo ${ }^{10}$. Poucas são as substâncias consideradas como drogas para a sociedade. Na cultura popular, as drogas são consideradas os produtos ilegais como maconha, crack, cocaína. Porém, tem-se conhecimento que drogas consideradas lícitas podem causar diversos agravos à saúde humana, como álcool, anabolizantes e medicamentos. O elevado consumo dessas substâncias tem sido um fator contribuinte para o aumento de vulnerabilidades física psicossocial da população do país ${ }^{11}$.

Diversos são os fatores geradores do envolvimento dos indivíduos com as drogas, como o seu o contexto social, facilidade de acesso, a presença das drogas em momentos festivos em família, falta de apoio social, questão financeira, dentre outros ${ }^{12}$.

Os adolescentes tornam-se a parcela da sociedade mais vulnerável ao uso abusivo das SPAs, visto que estão em uma transição psíquica e corporal, bem como apresentam a necessidade e anseios em experimentar o desconhecido, em viver novas experiências, que somadas, muitas vezes, as condições socioeconômicas, influência de amigos, contribui para potencializar o uso precoce e problemático das drogas ${ }^{13,14}$. 
Assim, embasados na literatura e no panorama epidemiológico do envolvimento de usuários, cada vez mais precoce, realizando uso abusivo de drogas, que o enfoque do PPLS em questão se pautou no caráter preventivo. As escolas do bairro foram escolhidas como cenário para as intervenções educativas e de sensibilização, buscando envolver discentes, familiar responsável e comunidade escolar, para propor ações que busquem ajudar a comunidade no enfrentamento do problema apontado.

No caso dos adultos, inúmeras podem ser as causas para o uso/abuso de substâncias psicoativas, como decepção, desemprego, doenças crônicas, contexto familiar ${ }^{12}$. Além disso, as drogas lícitas são, muitas vezes, utilizadas como válvula de escape para o enfretamento dos problemas pessoais, bem como atrativo para diversão e lazer. Acrescenta-se também, quantidade excessiva de bares em toda a região adscrita e a ausência de ambientes de lazer (praças, campo de futebol e outras) no território adscrito estudado.

A literatura aponta que promover ambientes que estimulem a adoção de comportamentos saudáveis é um fundamental para prevenção das drogas ${ }^{9,11}$. Dessa forma, alternativas podem ser criadas para evitar o uso abusivo das drogas, como: estímulo ao lazer, a religiosidade e ao apoio social positivo. Partindo dessa ideia, objetivou-se também no PPLS orientar a comunidade adscrita a USF a prática de exercícios físicos como alternativa para prevenção do uso/abuso de drogas.

A Atenção Básica tem papel imprescindível no reconhecimento desses adictos, trabalhando de forma integral, para atender as demandas e necessidades dos usuários. Acrescenta-se também o papel dos Agentes Comunitários de Saúde, que pela proximidade com a comunidade, pode identificar os problemas oriundos do uso de drogas, e ajudar a equipe nas intervenções precoces, utilizando os equipamentos socais existentes no bairro para planejar suas ações, ou até, mesmo, reconhecendo suas limitações e, quando necessário, realizar os encaminhamentos para outros pontos da rede SUS, os casos que carecem de ajuda especializada ${ }^{13}$.

Parte-se do pressuposto de uma educação mais sensibilizadora a respeito da temática com uma abordagem direcionada para os diferentes ciclos da vida (adolescentes e adultos).

A oficina é a demonstração dessa preocupação, e a participação popular é algo agregador com uma diversidade de opiniões e questionamentos, demonstrando os anseios desses indivíduos por melhorias, respeitando e incentivando sua participação ativa.

Outro ponto que merece destaque é o entendimento do estudante que a problemática das drogas merece uma atuação intersetorial e interdisciplinar, para que resultados em longo prazo possam ser mensurados. No entanto a visão do PPLS permitiu aos discentes elaborar e propor ações educativas em situação de saúde peculiar que impacta significativamente na comunidade. Assim, mesmo com baixa disponibilidade de recursos, e da peculiaridade do tema, são passíveis para intervir no pontinho do "iceberg", das drogas na atualidade.

\section{Conclusão}

Conclui-se que as ações traçadas relacionadas a temática álcool e drogas, apontada pela comunidade é uma tentativa de elaborar um planejamento local capaz de sensibilizar a população acerca dos problemas das drogas no território adscrita a uma Unidade de Saúde da Família.

Posto isso e na tentativa de que os discentes de medicina tenham familiaridade e compreendam o PPLS como ferramenta de gestão e planejamento participativo no SUS. O foco do planejamento das ações foi a educação em saúde acerca da temática álcool e outras drogas, a fim de atuar na prevenção e sensibilização da comunidade no seu contexto local.

Diante do PPLS, pretende-se prosseguir com a implementação das ações e construir junto com a comunidade medidas que tenham o intuito de minimizar a problemática vivenciada, seguindo o cronograma de ações propostas no planejamento. Além de incentivar que mais ações sejam desempenhadas para melhorar a condição de vida da população.

A aproximação dos acadêmicos com a realidade da população é imprescindível para a formação médica. Dessa forma, desde a oficina até a criação do PPLS, é notável o aprendizado do discente, desde a adequação da linguagem para facilitar o entendimento da população, além de compreender a realidade da comunidade.

\section{Referências}

1. 1. BRASIL. Portaria $\mathrm{n}-2.436$, de 21 de setembro de 2017. Aprova a Política Nacional de Atenção Básica, estabelecendo a revisão de 
diretrizes para a organização da Atenção Básica, no âmbito do Sistema Único de Saúde (SUS). Diário Oficial da União, Brasília, DF, 22 set. 2017. p. 68.

2. SANTANA ML., CARMAGNANI MI. Programa Saúde da Família no Brasil: um enfoque sobre seus pressupostos básicos, operacionalização e vantagens. Saúde e Sociedade, v. 10, n. 1, p. 33-53, 2001.

3. XAVIER LN, OLIVEIRA GLD, GOMES ADA, MACHADO MDFAS, ELOIA, SMC. Analisando as metodologias ativas na formação dos profissionais de saúde: uma revisão integrativa. SA N A R E, Sobral, V.13, n.1, p.76-83, jan./jun. 2014.

4. OLIVEIRA, DPR. Planejamento Estratégico: conceitos, metodologia e práticas. 23. ed. São Paulo: Atlas, 2007.

5. PLANEJAMENTO NA ATENÇÃO BÁSICA. 3. UNA-SUS. Florianópolis, 2013. [Acessado em 22 de maio de 2019]. Disponível em: https://unasus.ufsc.br/

6. BRITO CDS, RODRIGUES VP, MENDES, 4. LDS. O Planejamento e a Programação Local em Saúde como garantia do diagnóstico real das necessidades de saúde da Comunidade. Rev. Saúde Coletiva, v. 1, n.2, p. 157-162, 2005.

7. GOMES RMDL. Processo de Trabalho e 5. Planejamento na Estratégia Saúde da Família/ Rosa Maria de Lima Gomes - Recife: Ed. Universitária da UFPE, 2015.

8. VILASBOAS AL., TEIXEIRA CF. Manual para Treinamento Introdutório das Equipes de 6 Saúde da Família, Bahia. In: Bahia. Secretaria de Saúde do Estado da Bahia. Orientações metodológicas para o planejamento e programação das ações de vigilância da saúde nas áreas de abrangência do PACS-PSF. Salvador: Instituto de Saúde Coletiva da UFBA; 2001. p. 113-27.

1. 9. MALTA DC, MASCARENHAS MDM, PORTO DL, DUARTE EA, SARDINHA LM, Barreto $\mathrm{SM}$ et al. Prevalência do consumo de álcool e drogas entre adolescentes: análise dos dados da Pesquisa Nacional de Saúde Escolar. Rev. bras. Epidemiol, Sep, 2011.Instituto Brasileiro de Geografia e Estatística. Panorama nacional e internacional da produção de indicadores sociais: grupos populacionais específicos e uso do tempo, Rio de Janeiro, 2018. [Acesso em 12 de mar 2019]. Disponível em: https://www.ibge.gov.br

2. 10. SOUZA MR, SOUZA CR, DAHER CM, CALAIS L. Juventude e drogas: uma intervenção sob a perspectiva da Psicologia Social. Pesquisas e Práticas Psicossociais. v. 10, n.1, 2015.

11. FREIRES IDA, GOMES EMDA. O papel da família na prevenção ao uso de substâncias psicoativas. Rev Brasileira de Ciências da Saúde, v. 16, n.1, p; 99-104, 2012.

12. RODRIGUES E, ABAID J. Prevenção do uso de drogas no âmbito escolar: Uma revisão sistemática. Disciplinarum Scientia. Série: Ciências Humanas, Santa Maria, Santa Maria, v. 14, n. 2, p. 173-190, 2013.

13. CARDOSO MP, AGNOL, RD, TACCOLINI C, TANSINI K, VIEIRA A, HIRDES, A. A percepção dos usuários sobre a abordagem de álcool e outras drogas na atenção primária à saúde. Aletheia 45, p.72-86, set./dez. 2014

14. TELES L, CORREIA E, SCATTOLIN F. Percepções de Agentes Comunitários de Saúde sobre os usuários de álcool e outras drogas. Revista da Faculdade de Ciências Médicas e Sorocaba. v.18, n.2, p.92-97, fev. 2016.

\section{Endereço para Correspondência}

Faculdade Independente do Nordeste - FAINOR

Av. Luis Eduardo Magalhães, 1305 - Candeias

Vitória da Conquista (BA)

e-mail: lofernandez@gmail.com

Recebido em 17/11/2020

Aprovado em 27/02/2021

Publicado em 10/05/2021 